\title{
THE LIMITS OF SEEING AND KNOWING: EARLY MODERN ANATOMY AND THE UTERINE MEMBRANES
}

\section{Rebecca Whiteley}

little child sits, encircled by a translucent, egg-shaped container. His
knees are drawn up and gently clasped by his hands, his gaze is cast
down, and a small, knowing smile is on his lips (I668, figure I). ${ }^{\mathrm{I}}$ The cord emerging from his navel, which seems to twist and twine in invisible currents, indicates that this figure, depicted in a little engraving measuring $6 \mathrm{~cm}$ high and first printed as a book illustration in I668, is a fetus in amniotic fluid. ${ }^{2}$ We peer into his world through the protective, veiling, yet fragile, almost-not-there uterine membranes. He is, to us, both accessible and at an absolute remove, both exposed and veiled.

This image was produced for a midwifery manual by François Mauriceau, and it seemed to me, on first sight, to be an innovation - a strange new view of the fetus, not technically in utero, but 'in membranes'. Further research into early modern anatomical atlases, however, showed that this was not the case. In fact, what I term 'fetus-in-membranes' images formed a distinct and significant iconographic tradition in early modern anatomy. This article asks why there was such an interest in representing the fetus in membranes in the seventeenth and eighteenth centuries, and what such images said for contemporary viewers. I propose two main reasons for this preoccupation: firstly, that images of the membranes provided a locus for anatomists and artists to think through the skills and excellences, as well as the flaws and anxieties, of their disciplines; and secondly, that they spoke of a long-lasting but often tacit understanding of the bodily interior as unknown, a place of mystery.

This article will treat 'fetus-in-membranes' images made over a long period: from the first instance I have found, produced for Hieronymus Fabricius's De Formato Foetu (c. I600, figure 2), to those made for William Hunter's The Anatomy of the Human Gravid Uterus (1774, figures 6 and 7). ${ }^{3}$ Certainly, much 


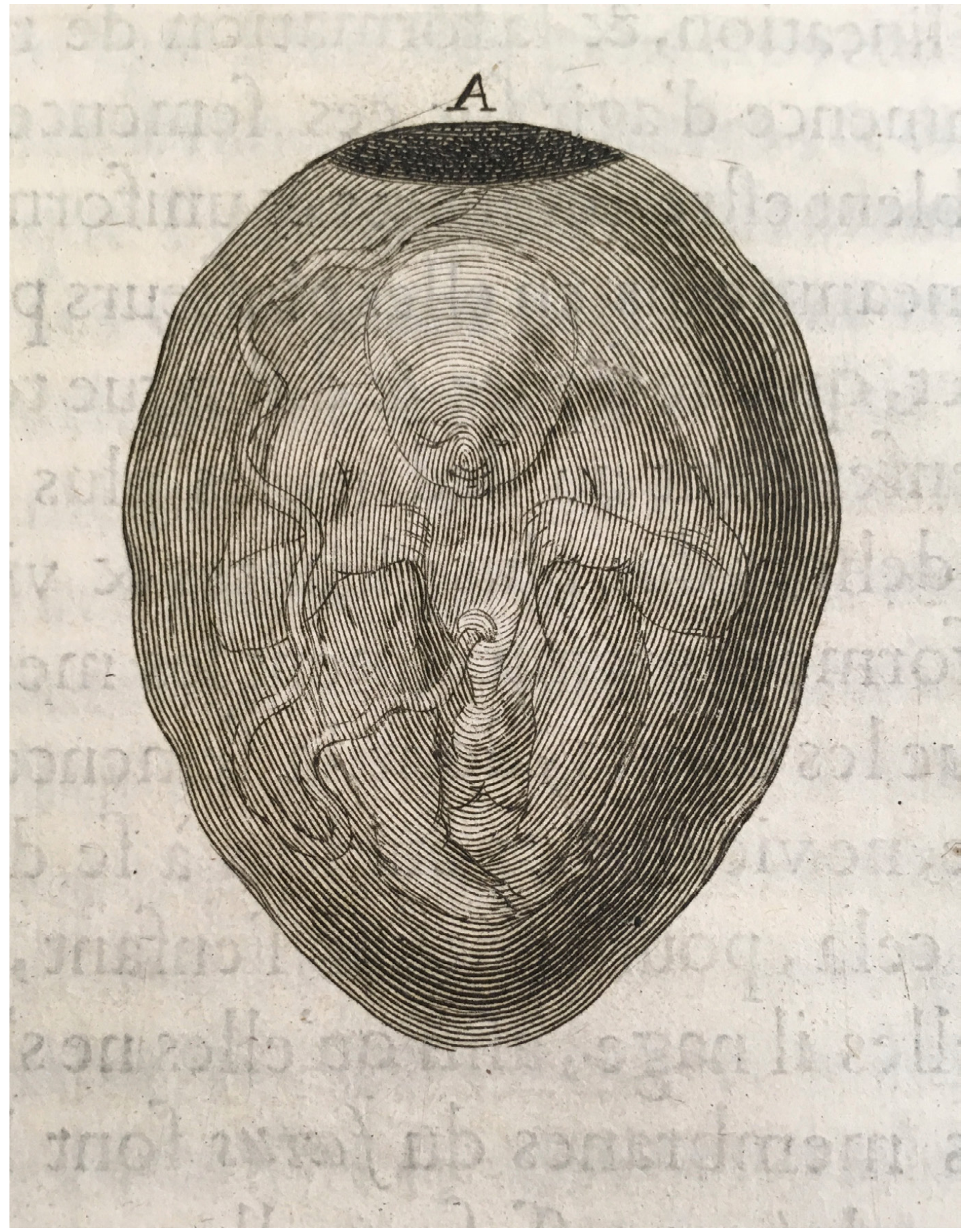

Figure I Anon., [fetus in uterine membranes], I668. Engraving, plate $10.3 \times 8.3 \mathrm{~cm}$, image $4.5 \times 6 \mathrm{~cm}$. From François Mauriceau, Des Maladies des Femmes Grosses et Accouchees, Paris, I668. Courtesy of the Wellcome Collection. Photo: the author. 
changed both in terms of how anatomical studies were conducted, and in how that knowledge was visually represented, over this 175 -year period. And yet, this was also a period characterised and bound together by new ideals in close first-hand observation of the dissected object, and detailed naturalistic representation of it. ${ }^{4}$ This article will argue that the persistent interest in the 'fetus-in-membranes' indicates a consistent anxiety about the anatomical project. Likewise, it will treat images originally produced in many Western European countries. While it is certainly the case that each country and region remained unique in its understanding of, approach to and treatment of the pregnant body, an increasingly shared academic culture also emerged in this period, as physicians, anatomists and midwives disseminated ideas and discoveries in letters and printed works. These prints' very mobility, circulating both physically and through processes of copying, produced a new kind of shared visual culture which meant that images originally produced in Germany, France, Italy, Spain or the Netherlands could all contribute to England's culture of the body, and vice versa.

$$
* * *
$$

The uterine membranes are a liminal part of the body: they both veil and expose, they protect and lay bare, they give the impression both of knowledge allowed and knowledge denied. In his book Pictures of the Body (I999), James Elkins finds the body's membranes troubling because they 'are skinlike but also wet and private': like the skin they delimit, they define the inside and the outside, yet they are also themselves an inside, a part of the mysterious bodily interior. 5 These contradictory, liminal and mysterious qualities of the uterine membranes so interested early modern anatomists and artists because they both provided a challenge for their skills, and a space in which to think through their limits and anxieties.

For anatomists, the uterine membranes had interesting symbolic and material properties. Discussing sixteenth-century anatomy, Katherine Park has argued that 'the female body - and the uterus in particular' was symbolically important as 'the ultimate natural secret'. ${ }^{6}$ The uterus was considered a strange, troublesome, perhaps autonomous organ that not only defined female anatomy, female health and female sexuality, but also concealed the secrets of human generation. ${ }^{7}$ And while, by the eighteenth century, the uterus had become a less active and less mystic force, it was still, 
as Ludmilla Jordanova has demonstrated, a prime object for the anatomist's attention. Early modern and Enlightenment anatomists exposed and depicted the uterus because they saw 'the emblematic core of their [women's] sex in the organs of generation'. ${ }^{8}$

Not only was the uterus symbolically compelling, it was also materially difficult to get hold of. Female, and particularly pregnant, corpses were hard for anatomists to acquire. Susan Staub suggests that only roughly Io\% of corpses acquired from the scaffold in England in the seventeenth century were female, though more might have been found through other means. 9 Jonathan Sawday, noting that the proportion of images of female anatomy is much higher than the proportion of dissections, suggests that the subject was particularly intriguing. ${ }^{\text {IO }}$ Images of the uterus and the fetus were prestigious because rare, and within this, images of the membranes were particularly special. During pregnancy, women produce two uterine membranes: the amnion and the chorion, which are separate and rather thick in early pregnancy, but which, by late pregnancy, have fused and stretched, becoming translucent and so fragile that they are 'easily ruptured with slight pressure from a plastic hook'. I These membranes contain the fetus, amniotic fluid and placenta, and form a lining between these and the walls of the uterus. While it is possible to cut through the uterine wall without cutting the membranes, it requires delicacy and skill. The exposure of the membranes, whole and unbroken, can be understood, therefore, as a mark of skill in the manual acts of dissection that were becoming increasingly valued at this time. ${ }^{\mathrm{I} 2}$

The challenge of obtaining pregnant subjects, and of exposing the uterine membranes, is perhaps what led Fabricius to have the first 'fetus-inmembranes' image produced (figure 2). In doing so, he provided a novel view of the female bodily interior and exhibited his own remarkable skills in uncovering and understanding its secrets. As Sawday has argued,

The surgeon seems to share the iconic status of the artist (or the visionary) within our culture, since both are held to be in possession of a privileged gaze which is able to pass beyond common experience, through surface structures, to encounter a reserved core of reality. ${ }^{\mathrm{I3}}$

Not only did the 'fetus-in-membranes' image evidence manual skills, it also symbolised the special gaze of the anatomist. This gaze sees through to the 


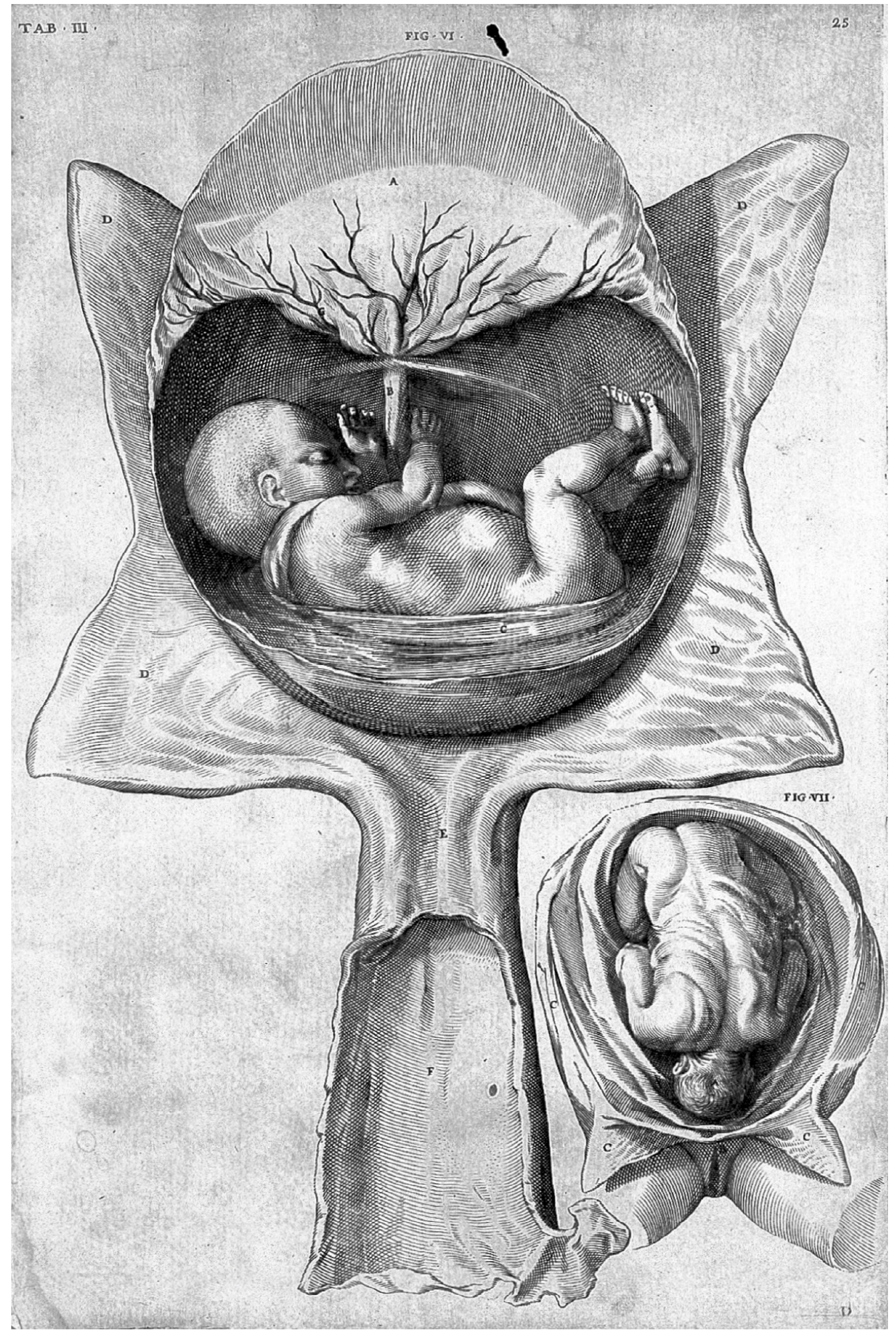

Figure 2 Anon., Tab. III., c. I600. Engraving, plate $26 \times 40 \mathrm{~cm}$. From Hieronymus Fabricius, De Formato Foetu, Padua, c. I60o. Courtesy of the Wellcome Collection. 
core, both literally, in its visual access to the bodily interior, and in its ability to sort, identify, regulate and explain what is seen.

According with Sawday's association of surgeon with artist, Fabricius's image is also one that speaks in valorising tones about the artist's sight, their special ability to see the body clearly, or differently, and to reproduce that special sight in an image. Fabricius' image is, given the date of production, almost certainly an imagined composite of information gathered from multiple dissections, rather than a description of one single subject. ${ }^{14}$ Indeed, there are some strange elements to the image that mark it as an imagined composition. The amniotic sac, for instance, appears to lie on the dissected uterus as if completely excised: a very difficult operation to manage. Moreover, while much of the amniotic fluid appears to have drained away, the membranes keep their globular shape. Through them, we see the fetus lying on its back, as if bathing in the fluid. These strange elements can be understood, however, as innovative techniques developed by the draftsman and engraver to represent the translucent membranes. The membranes themselves are not described, but rather implied by the way the fluid is shaped, rising against the membrane walls, and by the light glinting off their moist surface.

The decision to show the membranes 'half-filled' may also have served another purpose: describing not only how the body was seen in dissection, but how the living and visually inaccessible pregnant body was thought about. It was common in the seventeenth century to describe the membranes, as the midwifery author James Wolveridge does, 'in which sweat and urine are gathered together, in which the Infant swimmeth, and sits as safe as in a Bath'. ${ }^{\text {Is }}$ The 'bathing' fetus in Fabricius' image, therefore, engages with contemporary medical descriptive language. The strangeness of the fetus living in a watery environment is made more familiar by being placed in the context of domestic life. He seems to recline in the water, crossed heels and head resting against the uterine wall. The image, therefore, combines different modes of representation: naturalistic and observational representation of a dissection, combined with a system of analogy which gives narrative and logic to the bewildering, alien world of the bodily interior. ${ }^{16}$ This moving between representational modes demonstrates the anatomist's skills in dissection and observation as well as their skills in understanding and explaining.

But, if both anatomists and artists saw the 'fetus-in-membranes' image as a locus for thinking about and displaying professional skills, then it was also 
understood as a locus for thinking about and displaying professional anxieties, and particularly the anxiety that the body as it was known through dissection, was not exactly like that of the living and whole body. ${ }^{17}$ Dániel Margócsy has argued, for instance, that '[a]natomy and first-hand observation do not go well together. The human eye cannot see the internal structures of the living human body, hidden behind the skin'. ${ }^{18}$ The dead body no longer moved, it was rapidly decaying and, as it was opened to sight, it was also materially destroyed. Thus, what the anatomist saw, was not what the living body was actually like. Margócsy notes that early modern anatomists were especially troubled by the way that fluids, which give the living body both shape and dynamism, drained away when dissecting the dead. ${ }^{19}$ This problem was particularly evident when dissecting the pregnant body because, in opening the membranes and gaining direct visual access to the fetus, one also released the waters, irrevocably changing the fetal environment, its position within the body, and the shape of both membranes and uterus. The 'fetus-inmembranes' image, therefore, represents a liminal moment in the process of dissection, in which the anatomist can simultaneously see the fetus, partially, and yet still envision it as alive, or as it would be when alive and within the mother's body.

What these images offer is elucidated by an image of the broken membranes produced for Andreas Vesalius's De Humani Corporis Fabrica (I 543, figure 3a), and copied for Juan Valverde de Amusco's Historia de la composicion del cuerpo humano (I556, figure 3b). In Jan van Calcar's (probable draughtsman) version for Vesalius, we see an imagined interior in an atemporal space: the bodily elements retain shape and apparent life, despite being dissected and floating free of the bodily context. They look like they could be repeatedly separated and put back together again. Gaspar Becerra's (probable draftsman) version for Valverde, however, is much more material and temporal. The fetus and membranes remain floating and separated from the rest of the body, but now they hover at the feet of a full anatomical figure and above a grassy landscape. In this version, the fetus, instead of calmly floating with legs and arms crossed, seems to hunch over in discomfort, clutching at the umbilical cord around his neck. Adding to the sense of peril, amniotic fluid pours from the broken membranes onto the earth beneath. These alterations make the image more physical and material: the attitude of the fetus brings the image closer to the contingencies and dangers of childbirth, and the draining fluid 


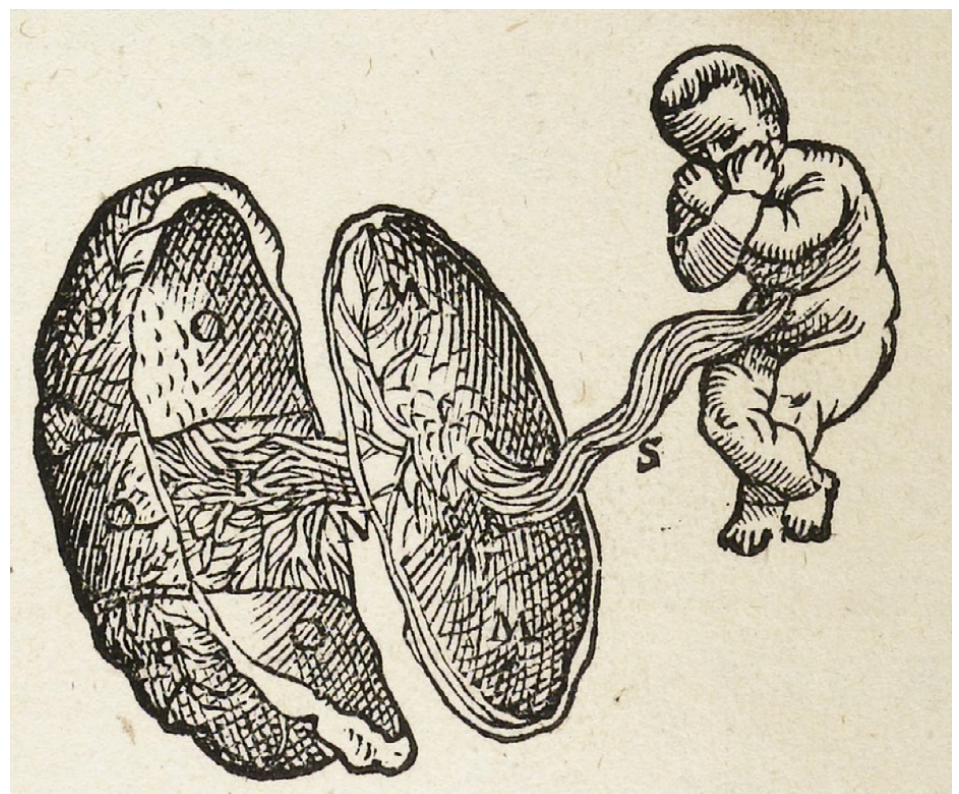

Figure 3a Jan van

Calcar, probable draftsman,

Trigesima Quinti Libri

Figura, I 543. Woodcut,

page $3 \mathrm{I} .8 \times 4 \mathrm{I} \mathrm{cm}$, image $6 \times 4.5 \mathrm{~cm}$. Detail. From Andreas Vesalius, De Humani Corporis Fabrica, Basel, I 543. Courtesy of the Wellcome Collection.

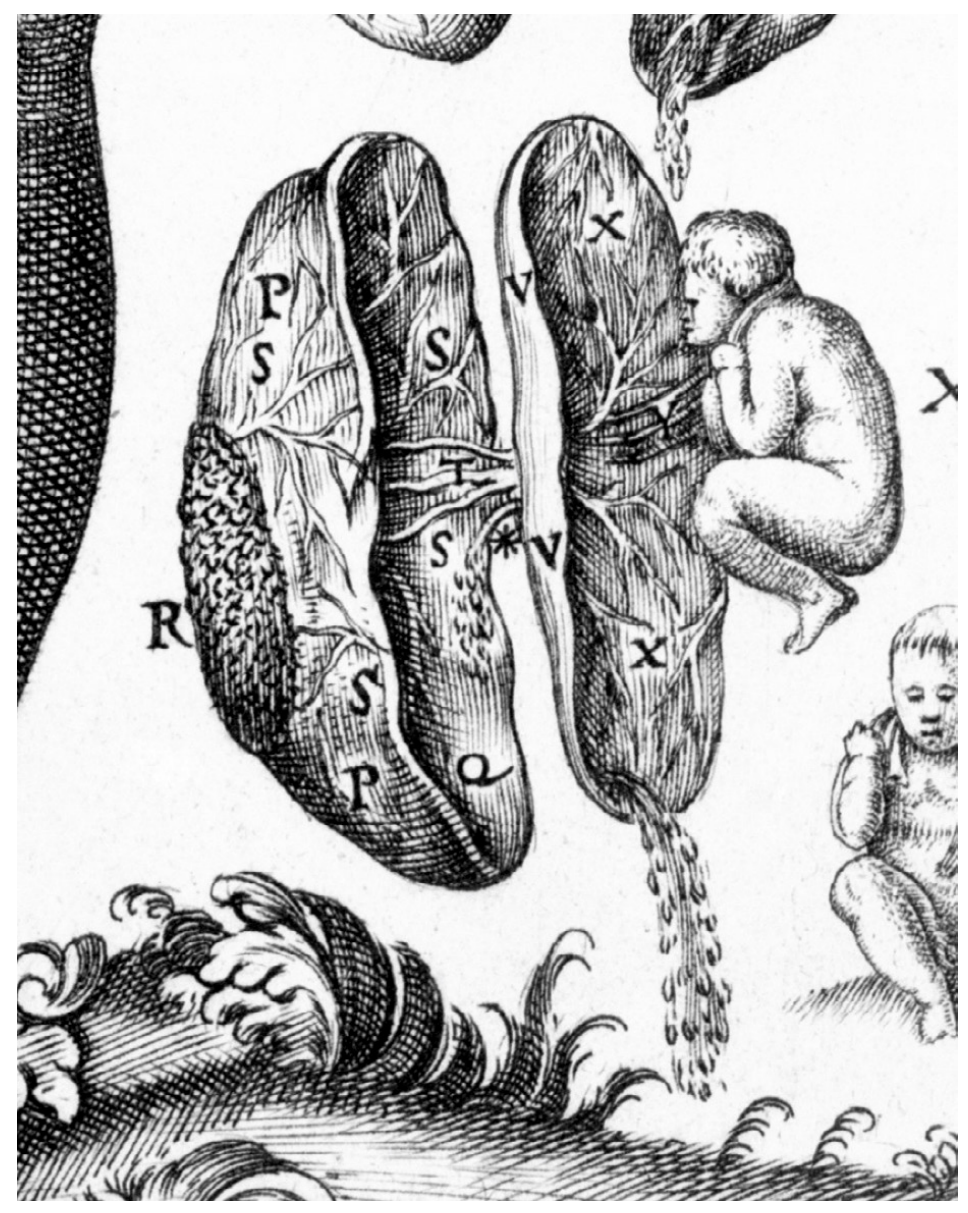

Figure 3b Gaspar

Becerra, probable

draftsman, Tauola. VI. del Lib. III., I 556. Engraving, plate I $5.6 \times 24.2 \mathrm{~cm}$, detail $3.6 \times 4 \mathrm{~cm}$. Detail. From Juan Valverde de Amusco, Historia de la composicion del cuerpo humano, Rome, I 556. Courtesy of the Wellcome Collection. 
to the terrible irrevocability of dissection. As the fluid trickles away onto the ground below, we know that the body cannot be put back together again - already it decays, the body returning to the earth. It is in counterpoint to such an awareness that the 'fetus-in-membranes' offers its liminal moment of seeing without destroying, of life on the cusp of death.

The membranes were particularly remarkable for this ability to display in the context of what Ludmilla Jordanova has identified as the early modern visual and perceptual metaphor in anatomy of 'unveiling': the 'assumption that anatomical and surgical knowledge unveils the human body'. ${ }^{20}$ This metaphor, she notes, is often expressed in frontispieces which feature veils and curtains of cloth elegantly drawn back. Mechthild Fend has further associated the skin itself with a veil: she argues that the physical act of skinremoval in dissection allowed those who conducted or witnessed dissections to develop an ability to 'see through' the living opaque body, to understand and picture how the interior worked and moved, to map that knowledge onto the living body. ${ }^{2 \mathrm{I}}$ Jordanova, Fend and Claudia Benthien further associate this veiling and unveiling specifically with the female body, which had long been understood as mysterious, troublesome, and less knowable than the male body. ${ }^{22}$ Of course, this unveiling of the female bodily interior was part of a wider misogynistic culture of control, which prescribed modesty in the veil, and found sexual titillation in the act of unveiling. ${ }^{23}$ As Jordanova argues, 'unveiling men makes no sense, possibly because neither mystery nor modesty are male preserves but are attributes of the other'. ${ }^{24}$

But while the skin is an opaque veil, either covering or drawn back, the membranes are teasingly translucent. Seen through, they offer both the idea of secrecy and covering, while also giving a glimpse of the interior. Claudia Benthien has described such a living, yet see-through body as the anatomist's ultimate ideal. ${ }^{25}$ While many images showed anatomically 'unveiled' bodies posed as if alive, even engaging in their own dissection and exposure, such images were clearly fantasies. What the 'fetus-in-membranes' image offered was a subtler, more teasing, more liminal and thus more fascinating space representing the single moment between veiled and unveiled, between life and death. Indeed, the text of William Hunter's The Anatomy of the Human Gravid Uterus (I774) suggests that the translucency of the membrane and its capacity to protect and expose were considered its most compelling attributes. Hunter almost never writes the word 'membrane' without the adjective 


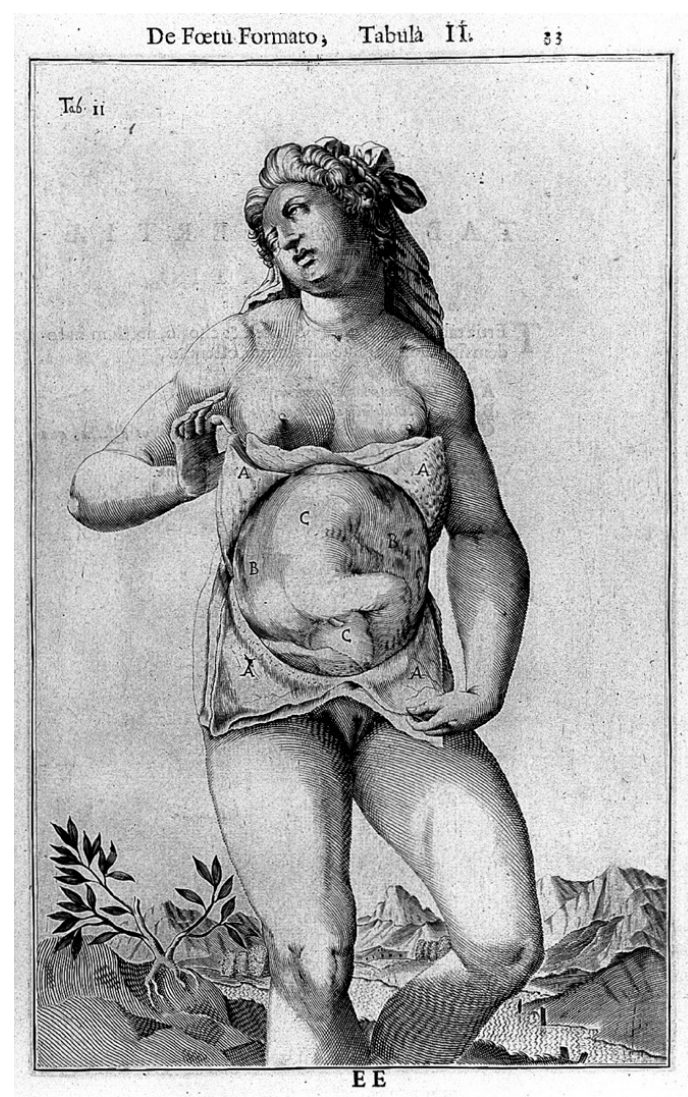

Figure 4a Odoardo Fialetti, draftsman, Tabula II., I645. Engraving, plate 21.5 $\times$ $34 \mathrm{~cm}$. Courtesy of the Wellcome Collection.

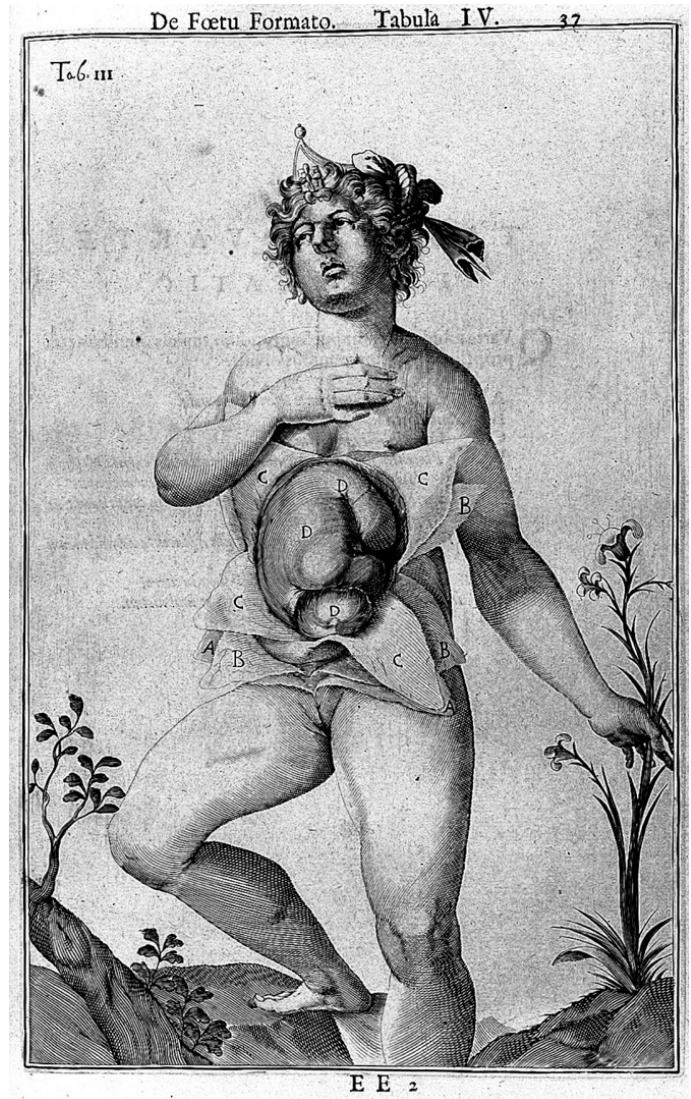

Figure $\mathbf{4} \mathbf{b}$ Odoardo Fialetti, draftsman, Tabula IV., I645. Engraving, plate 2 I. $5 \times$ $34 \mathrm{~cm}$. From Adriaan van de Spiegel and Giulio Cesare Casseri, De Formato Foetu, Amsterdam, I645. Courtesy of the Wellcome Collection.

'transparent', and repeatedly describes how 'distinctly' or 'obscurely' things are seen through them. ${ }^{26}$

Images of the membranes offered a space for thinking through these problems of seeing and knowing, as can be seen in the anatomical images produced by Odoardo Fialetti for Adriaan van den Spiegel's and Giulio Cesare Casseri's De Formato Foetu Liber Singularis (I626, figures 4a and 4b), and in the anatomical fugitive sheet titled 'Autumnus' (seventeenth century, figure 5). Fialetti's series of anatomical figures show living women who expose their interiors by peeling back their own skin. The second of four full-length anatomies shows the membranes, represented by gently swirling hatched lines that simultaneously describe and obscure the fetus beneath (figure 4a). 
If this image teases the inquisitive sight of the anatomist, however, both unveiling and veiling simultaneously, then curiosity is satisfied by turning the page, and viewing the next image which shows the fetus exposed (figure $4 \mathrm{~b}$ ). As a group, the four images mimic the process of dissection: the turning of the page mirroring the peeling back of skin, muscle and membrane in a kind of anatomical strip tease. Here the viewer's desire to open up and see, without damaging, is catered to with a clean, bloodless dissection: tactile, but abstracted and aestheticised.

The same material play with the paper body is possible with the anatomical sheet 'Autumnus' (figure 5). The sheet shows a male and a female figure, each with anatomical interiors comprised of multiple flaps of printed paper, layered over each other. The figures are surrounded by visual information of all kinds, from astrology and botany to uroscopy and alchemy. Here, anatomy is only one of multiple modes through which the body can be known. ${ }^{27}$ Paper technologies, such as flaps and volvelles, are used in these sheets to create a rich, materially engaging representation of the body and the world. The membrane's flap, as usual, seems to have been a problematic element within the system of representation. This flap shows the outline of the fetus, covered with gently waving hatched lines that simultaneously obscure, and make it manifest. The flap below shows the same fetus, this time in crisper detail. Yet the fact that the fetus had to be drawn on the membranes flap, because paper is not actually see-through, seems to have troubled the artist. He addressed this problem by cutting a little hole in the membranes flap, exposing the crown of the fetal head beneath. There is something quietly humorous about this addition: the artist draws the viewer into a consciousness of the play in which they engage, not just lifting and closing flaps, but playing peek-a-boo with the fetus. Indeed, this flap provides a kind of meta-material commentary on the sheet of which it is part. ${ }^{28}$ The hole reminds us of the material dissimilarity between paper and membrane. Paper is opaque, it is hardy, and, as the support on which text and image is printed, it is a public, mobile material, the conveyor of information. Membranes, on the other hand, are translucent and fragile - hidden within the body, they are private and they do not display and disseminate, but contain and veil. We should, I argue, take the flap and hole all-in-all: together, they represent not only what the membranes look like, but what they are: liminal and mysterious, simultaneously there and not there. 


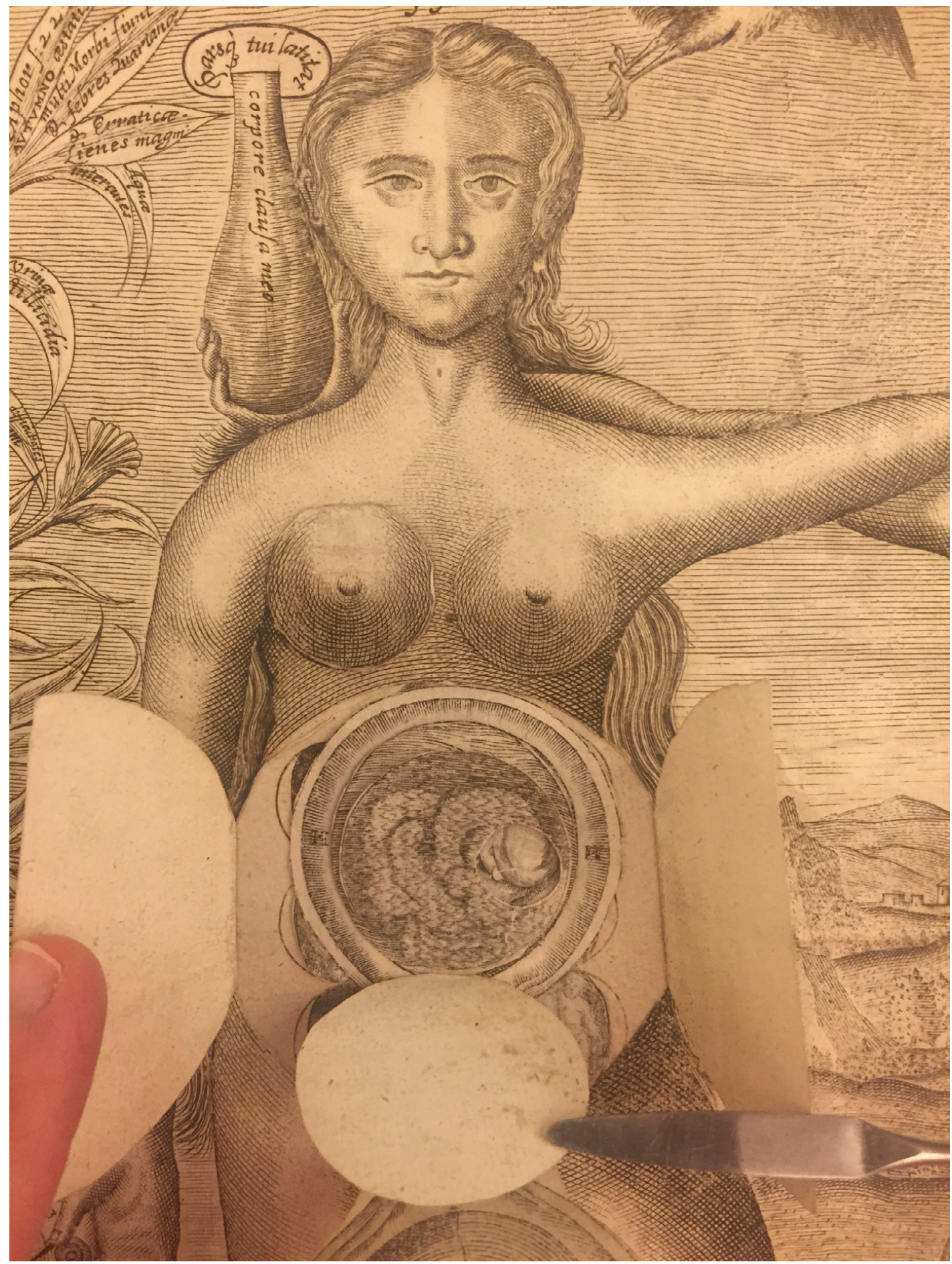

Figure 5 Anon., AUTUMNUS, Four Seasons, seventeenth century. Engraving, plate $35 \times 45 \mathrm{~cm}$. Detail. Courtesy of History of Medicine Collections, David M. Rubenstein Rare Book \& Manuscript Library, Duke University, Durham, NC, USA. Photo: Rachel Ingold. 
As the seventeenth century closed and the eighteenth century began, other anatomists such as Govert Bidloo and Charles Nicholas Jenty turned their attention to images of the membranes, also approaching them as a means to think through the complexities of their professions, and the processes of representation. ${ }^{29}$ But it was, perhaps, the images produced for William Hunter's atlas that took best advantage of the subject. Hunter's atlas has been, comparatively, much discussed by historians of art and medicine. Scholars such as Massey, Jordanova, Martin Kemp, Roberta McGrath, Lorraine Daston and Peter Galison, have all examined Hunter's approach to anatomical illustration. ${ }^{30}$ They all investigate Hunter's commitment to what he called the 'simple portrait, in which the object is represented exactly as it was seen'. ${ }^{31}$ This approach differed from that of earlier anatomical artists, who tended to produce composite images, informed by one or multiple dissections, which generalised or idealised the body. ${ }^{32}$ Part of Hunter's ideal was of an artist stripped of as much agency and creative faculty as possible - in Lyle Massey's words, 'a mere conduit of pure empiricism, acting as nothing more than a competent scribe'. ${ }^{33}$ Of course, this is not an ideal art historians tend to believe achievable, and I argue that images of the membranes in Hunter's atlas actually provided a particularly fruitful ground for the artists to exercise their creative faculties.

Hunter declared that his images bore 'the mark of truth' because they were direct copies, and so became truthful in a new way - 'almost as infallible as the object itself.${ }^{34}$ However, further investigation of the plates demonstrates an awareness on the part of both anatomist and artists of the more complex relations between object and image. In Table 2 I (figure 6), for instance, we find an image that on first inspection seems to adhere closely to Hunter's ideal of the observed specimen. Rather than fully exposed membranes, this image depicts only a small crucial incision in the uterine wall, out of which a portion of the membranes bulges. This is a stark indication of their fragility and the difficulty with which they would be completely excised. Much as Fabricius's image had done, Hunter's makes a claim for his skills in dissection, observation and understanding, but here the claim is shaped by Hunter's own severe Enlightenment commitment to the single observed specimen. However, if the image makes a visual argument for its 'infallibility', then Hunter's accompanying text betrays the gap that always remains between object an image. He describes how '[i]n this angle between the womb and 


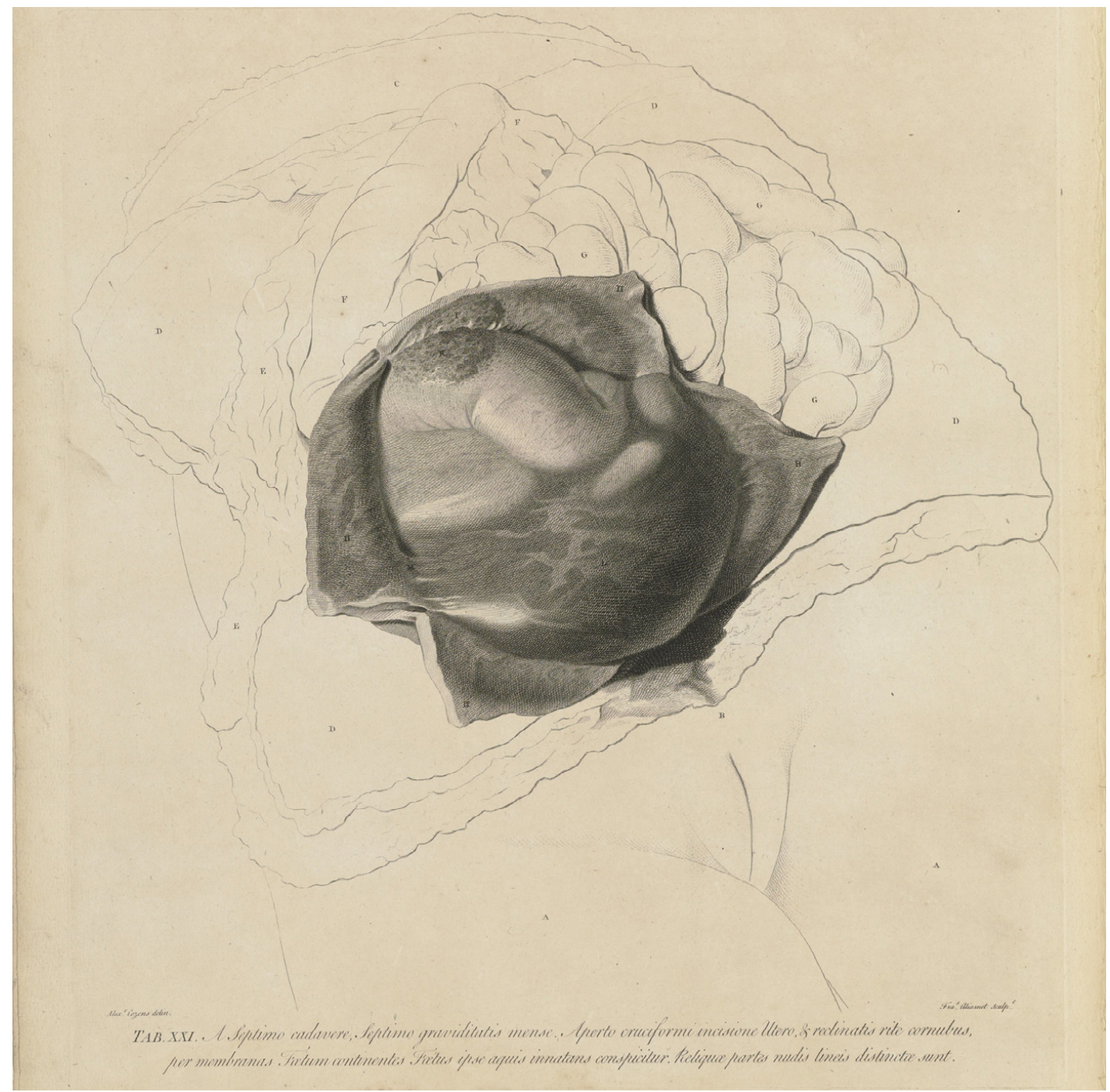

Figure 6 Alexander Cozens, draftsman and François-Germain Aliamet, engraver, Tab. XXI., I 774. Engraving, plate $43.7 \times 48 \mathrm{~cm}$. From William Hunter, The Anatomy of the Human Gravid Uterus Exhibited in Figures, Birmingham, I774. Courtesy of the Wellcome Collection.

the secundines, the artist endeavoured to express what was very apparent in the object, viz. the continuity of the substance of the womb and of the secundines' ${ }^{35}$ In his acknowledgement of the artist's hard work, Hunter also acknowledges the creative work of translation and representation that links object to image, as well as the inevitable gap that separates the two.

For Hunter, the membranes were worth commenting on because their translucency made them a difficult subject to represent. But for the draftsman, 
Alexander Cozens, and the engraver, François-Germain Aliamet, the membranes provided a way to reflect more widely on the nature and history of their discipline. ${ }^{36}$ Hunter's representational ideals are often associated with the atlas's highly detailed, tonal naturalism. Yet here, as in others of the plates, outline is also employed, acknowledging the existence of multiple modes for representing the body. The great white expanses of the background and the corpse's skin encourage our eye toward the centre of the image: the uterine membranes, represented in velvety-rich tone. This technique creates a strange material contradiction, akin to that of the 'Autumnus' membranes flap with its hole (figure 5): what is intended to be read as solid, unpenetrated flesh, is represented by almost-blank paper, while what is rendered in a thick mesh of inked lines, is meant to be read as see-through. The artists again highlight the difference between paper and membrane, and more widely between image and object. In this image, what is most ephemeral, most penetrable by the eye - the membrane - is, in terms of ink and paper, the most material, and the most present. Again, the materiality of the print makes us aware of the difference between paper and membrane, as well as between the image which exposes, and the membrane which veils. It is almost as if the more the artists focus, the more detail with which they represent, and the closer they try to get to the eventual subject - the fetus - the more obscure things become. As the eye travels from the blank outer to the inked inner, things become smaller, darker and more complex: the membranes work to complicate and baffle the Enlightenment investigative ideal.

Moreover, the body, rendered merely in outline, assumes the creamy white of marble sculpture. The reclined position and the neat and hairless pudenda add to the classicising feel. Against this, the opened interior, bulging darkly from the seemingly stony exterior, is doubly surprising. The solid exterior gives way to a soft and fleshy interior, both much more material and much more alive. Perhaps, in this image, Aliamet and Cozens were looking back to Vesalius and the tradition of representing organs in hollow classical torsos. But while Vesalius used classical sculpture to make an argument for the legitimacy of his images, the artists here seem to see a classicised exterior as dull and superficial compared to what lies beneath. ${ }^{37}$ Reproducing, instead, the specific way that the anatomist sees the body, they skim over the smooth perfection of the exterior skin, zeroing-in with a deep and intense interest on the workings of the interior. In this valorising of the anatomist's way of 
seeing and knowing, the artists also highlight what Hunter wished to avoid acknowledging - that there is no such thing as 'the simple portrait, in which the object is represented exactly as it was seen': there are only many and various ways of seeing, and of representing. ${ }^{38}$

Another image from Hunter's atlas, one of several small figures from Table 26, depicts the uterus, excised from the maternal body, and with a small 'window' cut into it, exposing the membranes (figure 7). Another window, the twelve-paned window in Hunter's dissecting room, can also be seen reflected in the membranes' surface. Massey, following Hunter's rhetoric, describes the window as 'a temporal signifier that testifies to the artist's presence in the dissection theatre and therefore to the reality on which the image is based'. ${ }^{39}$ McGrath notes that the window might also act as an 'unintentional reminder of the grid of the image, of the way in which viewers saw through a screen, both literally and metaphorically'.40 She declares that this reference to the image must be unintentional because, for Hunter, '[a]ll transcription was to serve the end of faithful representation'.${ }^{4 \mathrm{I}}$ McGrath not only underestimates Hunter's awareness of the image-making process by confusing his rhetoric with his understanding, she also denies any agency at all to the artist and the engraver. I argue, rather, that for the draftsman, Jan van Rymsdyck, and the engraver, Aliamet, the window, as a reminder of the way that viewers 'saw through a screen, both literally and metaphorically', was an entirely intentional allusion.

In this image, the membranes are both mirror and window, reflecting the image of a window, as well as functioning as a window onto the fetus within. Within classical art theory, art itself was often compared to both a mirror and a window onto the world. ${ }^{42}$ Thus, the membranes become a symbol of representation itself, both reflecting the exterior world, and exposing the interior microcosmic world of the body. This was a period in which a microcosmic understanding of the body was widespread. It provided systems for understanding - through comparison and analogy - both what went on in the body, and in the world. ${ }^{43}$ Within this system, the fetus was both a miniature microcosmic person, and a microcosm in itself. Gazing through the membranes, therefore, the viewer saw both a tiny world, and a reflection of the world at large. The membranes were a kind of natural barrier working both within and between worlds. As the anatomist Helkiah Crooke put it in his anatomical text of I6I5: 


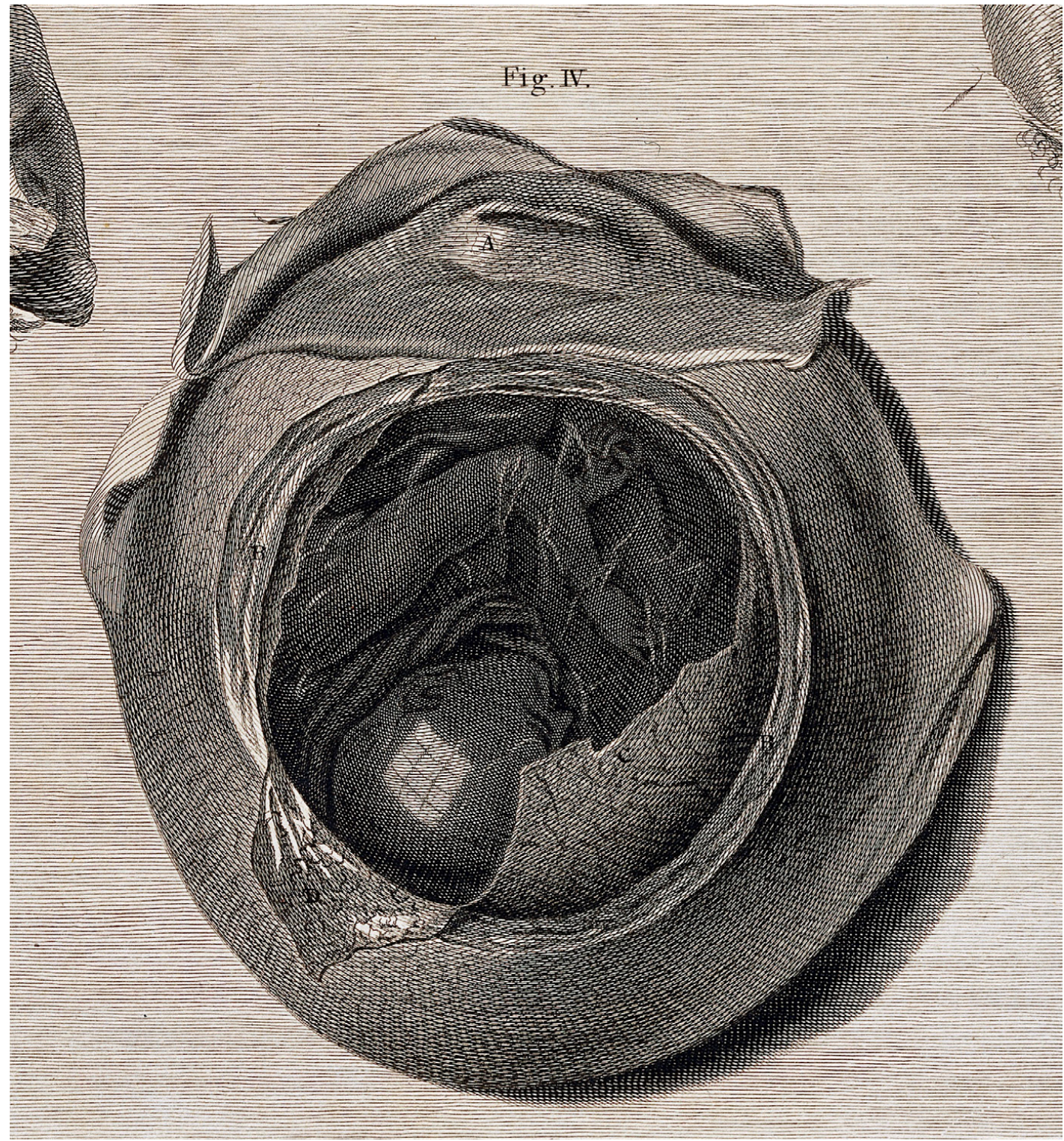

Figure 7 Jan van Rymsdyck, draftsman and François-Germain Aliamet, engraver, Tab. XXVI, I774. Engraving, plate $4 \mathrm{I} .3 \times 54.4 \mathrm{~cm}$, detail I $6.5 \times$ I $7.5 \mathrm{~cm}$. Detail. From William Hunter, The Anatomy of the Human Gravid Uterus Exhibited in Figures, Birmingham, I774. Courtesy of the Wellcome Collection.

even as God in the great World hath separated the fire from the earth by the interposition of water and air, so in the Microcosm or little World, the Nature of man imitating the grand Architect hath separated the Infant from the Womb by the interposition of these membranes. ${ }^{44}$ 
The reflection of the window in Table 26 labels the membranes as a literal and philosophical window: a mystical portal onto the invisible interior, and to a deeper understanding of the body and the universe.

$$
* * *
$$

This article has investigated the ways in which anatomists and artists used the uterine membranes to think through the processes and the implications of anatomical knowledge-making, and particularly the production of images. It is this complex understanding that must be brought to bear when returning to the image with which I began, the 'fetus-in-membranes' printed in Mauriceau's midwifery manual (figure I). A surgeon and a midwife, Mauriceau adopted this iconography from anatomy to legitimise and professionalise his own status, but perhaps also to nuance and problematise it.

The seventeenth century saw, for the first time, the rise of the medically trained 'man-midwife' in England, or 'accoucheur' in France. These men, who previously had been called to labours only in the direst of emergencies, attempted to create for themselves a regular practice by professionalising and medicalising midwifery, and by arguing for the unsuitability of female practitioners. Incorporating information and imagery from medicine, surgery and anatomy into their published midwifery manuals was one of the many ways in which these first man-midwives undertook this project. ${ }^{45} \mathrm{By}$ adopting the 'fetus-in-membranes' image, Mauriceau made statements both about his rarefied knowledge of the bodily interior, and his technical skills: if the exposed membranes demonstrated the dexterity of the anatomist, they could arguably do the same for the midwife.

However, anatomical information and iconography was not simply adopted by midwife-authors; it was also adapted by them to suit their own aims and perceptions of the body. As Cynthia Klestinec has discussed in the case of surgery, anatomy in this period was problematic: on the one hand, it provided a foundational knowledge for the surgeon's art, yet on the other, it was associated with death and destruction of the body. Surgeons, she argues, as early as the sixteenth century, were keen 'to correct a somewhat ominous double vision, one that blurs the distinction between the anatomist and the surgeon with respect to his knives, cutting, and objectified bodies' ${ }^{46}$ The same was true of midwives of both genders writing in the seventeenth and eighteenth centuries: while anatomical knowledge was important, so was the 
distinction between anatomy and midwifery. As the English midwife Sarah Stone argued in her midwifery manual, 'dissecting the Dead, and being just and tender to the Living, are vastly different'. ${ }^{47}$ So, if we see in Mauriceau's image a valorisation of anatomical knowledge and technical skills in dissection, we also see a challenge to these ideals. On the one hand, this is an image that shows what the interior looks like: it gives a view of the normally mysterious hidden interior. But the veiling/exposing capacity of the membranes also makes this an image about non-visual knowledge, about the living bodily interior that is known hazily, at a distance, and primarily through touch.

Midwifery, in this period, was a practice that relied primarily on touch. All attendants, and particularly male midwives, had very limited visual access to the body. Typically, the labouring woman would remain clothed, and examinations would be conducted using the hand, passed under a sheet that protected the woman's exposed legs and genitalia from dangerous draughts and prying eyes alike. ${ }^{48}$ Checking the dilation of the cervix, aiding in the turning or delivering of the infant, and fetching away the placenta were all inherently non-visual interventions upon the bodily interior. Midwives of both genders, in an attempt to legitimise and make acceptable this kind of touch, valorised both their hands as a specially adapted tool, and the kind of touch they produced, as sensitive, skilled and appropriate. ${ }^{49}$ Indeed, Eve Keller has argued that the midwife's hand became, in this period, both 'a sign of almost magical prowess' and 'the place where the modern image of the medical miracle-worker is born'. so

Mauriceau's artist turned to the liminal 'fetus-in-membranes' image to communicate both the visually understood body of anatomy, and the haptically understood body of midwifery. He employed a rather unusual engraving technique, sometimes called à une taille, in which the image is rendered using a single spiralling line, which varies in thickness. In this case, the outline of the fetus has been lightly sketched, but over this a single spiralling line both describes the membranes, and the contours of the fetus within. Rebecca Zorach has discussed this technique in the context of its most famous seventeenth-century practitioner, the French engraver Claude Mellan. She argues that it formed part of a movement in printmaking away from the description of outline and towards that of contour - away from simply how something was seen, and towards how it existed in space. ${ }^{51}$ Of Mellan's most famous use of the à une taille technique, in The Veil of Saint 
Veronica (I649, figure 8), Zorach notes that the spiralling line which at once describes Christ's face and the cloth on which the image was miraculously imprinted, ripples subtly, as if communicating 'the soft pressure of the body against sheer woven fabric stretched thin'. ${ }^{52}$ Zorach argues that because the line describes contour, not outline, it is unclear whether we are looking at Christ's face pressed to the cloth, or the image that pressing produced: the image 'shimmer[s] between ink and embodiment'. ${ }^{53}$ In Mauriceau's image, too, the line that describes the membrane also makes manifest the fetus. This image describes not only what the fetus looks like through the membranes, but how it is felt through them, as the bent head and drawn-up knees press against the maternal body. This image 'embodies' the fetus in utero, communicating the way in which the midwife knows the living and closed body: subtly, hazily, and through touch. Indeed, it is hard not to recognise the spiralling line as the whorl of finger ridges, as if an enormous thumb had been carefully placed over the fetus, pressing and receiving impression. The membranes symbolise, for Mauriceau, the anatomical skills of opening, seeing and knowing, but also the midwife's commitment to bodily integrity and mystery, to knowing minimally and through touch.

Early modern anatomy is most often characterised by a fierce and singleminded commitment to visual investigation. Jonathan Sawday, for instance, argues that " $[t]$ he "heroic age" of scientific discovery [...] was a voracious consumer of the vestiges of the human frame'. ${ }^{54}$ He ascribes to early modern anatomy a violent commitment to acquiring visual knowledge, a predatory disregard of the flesh under investigation, a willingness to induce fear and horror in pursuit of its goals. Of Enlightenment and modern anatomy, Michel Foucault's ideal of the 'clinical gaze', fiercely disinterested in its illumination of the dark interior, has come to dominate our thinking. ${ }^{55}$ Yet these approaches overlook hesitancy and doubt in the anatomical investigative project, as well as the fact that the anatomical mode of knowing was, in this period, far from having hegemony over body knowledge. Rather, as Barbara Duden has argued, it contended with multiple modes of knowing: seeing and touching, but also thinking analogically and metaphorically. ${ }^{56}$ The membranes, in their liminality, served artists and practitioners of all kinds in the thinking round and through these modes. For us, too, these images offer a 'way-into' this complex culture, and a challenge to the dominant narratives of anatomical and body history. Here we see both the voracious gaze of 


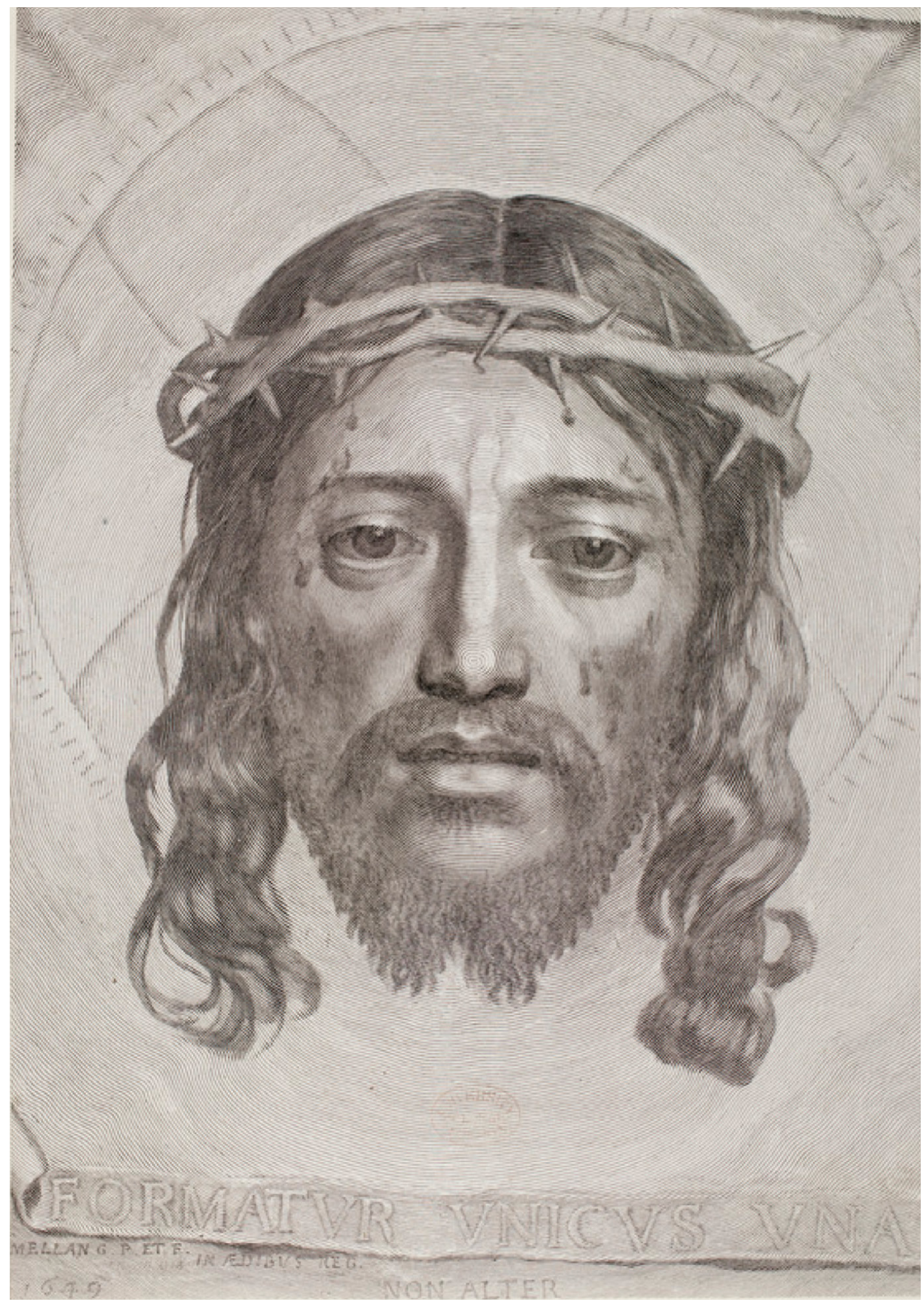

Figure 8 Claude Mellan, draftsman and engraver, The Veil of Saint Veronica, I649. Engraving, 3 I. $\times 42.9 \mathrm{~cm}$. Courtesy of UCL Art Museum, University College London. 
Sawday and Foucault, and its check - the uncertainties, the troubles, the taboos and the alternatives to this anatomical looking - and importantly, we see them together, in one image that manifests the variety of early modern body culture.

\section{Notes}

I would like to thank my supervisor Mechthild Fend for all her help, advice and encouragement in the writing of this article, and Christina Racek, M.D. for sharing with me her first-hand experience of the material qualities of the uterine membranes. Thanks must go, too, to The Huntington Library, San Marino for allowing me access to their rare materials collections, as well as the opportunity to talk through an early version of this article with their research community; and to the London Arts and Humanities Partnership for funding this research.

I As in this case, most images of the fetus produced in this period show a male. Reasons for this tendency include both the general social and cultural preference for boys (see for example Kate Retford, The Art of Domestic Life: Family Portraiture in EighteenthCentury England, New Haven and London, 2006, p. I00) and the widespread understanding that boys were physically more perfect (see for example Jane Sharp, The Midwives Book, London, I67I, p. I68).

2 This image was first printed in François Mauriceau, Traité des Maladies des Femmes Grosses et Accouchées, Paris, I668. It was published in every subsequent edition, including all English translations from I672.

3 In this article, I identify images using the draftsmen's and engravers' names when known, and otherwise by the name of the author of the book in which they were first published.

4 For detailed explorations of this theme see, for example Andrew Cunningham, The Anatomist Anatomis'd: An Experimental Discipline in Enlightenment Europe, Farnham and Burlington, 20 Iо; Lorraine Daston and Peter Galison, Objectivity, New York, 20 Iо; Lorraine Daston and Elizabeth Lunbeck (eds), Histories of Scientific Observation, Chicago and London, 20I I; Lyle Massey, "Against the "Statue Anatomized": the "Art" of Eighteenth-Century Anatomy on Trial' in Art History, vol. 40, no. I, 2017, pp. 68-103; Jonathan Sawday, The Body Emblazoned: Dissection and the Human Body in Renaissance Culture, London and New York, I995; and Charles T. Wolfe and Ofer Gal (eds), The Body as Object and Instrument of Knowledge: Embodied Empiricism in Early Modern Science, Dordrecht, Heidelberg, London and New York, 20 Io.

5 James Elkins, Pictures of the Body: Pain and Metamorphosis, Stanford, I999, p. 38.

6 Katherine Park, Secrets of Women: Gender, Generation, and the Origins of Human Dissection, New York, 20I0, p. I69.

7 For histories of the uterus, the female body and sexuality in the early modern period 
see also Laurinda Dixon, Perilous Chastity: Women and Illness in Pre-Enlightenment Art and Medicine, Ithaca and London, 1995; Barbara Duden, The Woman Beneath the Skin: A Doctor's Patients in Eighteenth-Century Germany, (trans.) Thomas Dunlap, Cambridge, MA., I99I; Mary Fissell, Vernacular Bodies: The Politics of Reproduction in Early Modern England, Oxford, 2004; Laura Gowing, Common Bodies: Women, Touch and Power in Seventeenth-Century England, New Haven and London, 2003; Eve Keller, Generating Bodies and Gendered Selves: The Rhetoric of Reproduction in Early Modern England, Seattle, 2007; Thomas Laqueur, Making Sex: Body and Gender from the Greeks to Freud. Cambridge, MA. and London, I990; Roberta McGrath, Seeing Her Sex: Medical Archives and the Female Body, Manchester and New York, 2002.

8 Ludmilla Jordanova, Sexual Visions: Images of Gender in Science and Medicine Between the Eighteenth and Twentieth Centuries, New York, I989, p. 58.

9 Susan C. Staub, 'Surveilling the Secrets of the Female Body: the Context for Reproductive Authority in the Popular Press of the Seventeenth Century' in Andrew Mangham and Greta Depledge (eds), The Female Body in Medicine and Literature, Liverpool, 20I I, pp. 5I-68, p. 55. Corpses may also have been stolen or illegally purchased, and sometimes permission to conduct a dissection or autopsy was given by family members.

Io Sawday, op. cit., pp. 220-22 I.

I I Christina M. Racek, MD., email communication, 25 September 20 I6.

I2 See Cynthia Klestinec, 'Practical Experience in Anatomy', in Wolfe and Gal (eds), op. cit., pp. $33^{-58}$.

I3 Sawday, op. cit., p. I2.

I4 Govert Bidloo's atlas of I 685 is often credited as the first to produce anatomical images of single dissected specimens. See Lyle Massey, 'Pregnancy and Pathology: Picturing Childbirth in Eighteenth-Century Obstetric Atlases', in The Art Bulletin, vol. 87, no. I, 2005, pp. 73-9I, p. 80.

I5 [James Wolveridge], The English Midwife Enlarged, London, I682, p. Iо.

I6 Rebecca Whiteley, 'Figuring Pictures and Picturing Figures: Images of the Pregnant Body and the Unborn Child in England, I540-c. I680', in Social History of Medicine, https://doi.org/I0.I093/shm/hkxo82 (accessed 29 October 20I7).

I7 See Cunningham, op. cit., p. 56.

I 8 Dániel Margócsy, Commercial Visions: Science, Trade, and Visual Culture in the Dutch Golden Age, Chicago and London, 2014, p. I37.

I9 Ibid., p. I38.

20 Jordanova, op. cit., p. 99.

2 I Mechthild Fend, Fleshing Out Surfaces: Skin in French Art and Medicine, 1650-1850, Manchester, 20I7, pp. 227-228.

22 Claudia Benthien, Skin: On the Cultural Border Between Self and the World, (trans.) Thomas Dunlap, New York, NY, 2002, p. 64.

23 Jordanova, op. cit., pp. 87-I I0.

24 Jordanova, op. cit., p. I Iо.

25 Benthien, op. cit., p. 48.

26 William Hunter, The Anatomy of the Human Gravid Uterus Exhibited in Figures, London, I774. 
27 For a detailed discussion of the kinds of knowledge and the modes of representation in these four prints, see H.F.J. Horstmanshoff, A.M. Luyendijk-Elshout and F.G. Schlesinger (eds), The Four Seasons of Human Life: Four Anonymous Engravings from the Trent Collection, Rotterdam and Durham, NC, 2002.

28 For a discussion of the 'metapictorial' in the seventeenth century, see Victor I. Stoichita, The Self-Aware Image: An Insight into Early Modern Metapainting, London, 2015 .

29 See Govert Bidloo, Anatomia Humani Corporis, Amsterdam, I685, Tables 56-63; and Charles Nicholas Jenty, The Demonstrations of a Pregnant Uterus of a Woman at Her Full Time, London, 1758.

30 Daston and Galison, op. cit.; Jordanova, op. cit.; Martin Kemp, 'True to Their Natures: Sir Joshua Reynolds and Dr William Hunter at the Royal Academy of Arts', in Notes and Records of the Royal Society of London, vol. 46, no. I, I992, pp. 77-88; Massey, op. cit., 2005 and McGrath, op. cit.

3 I Hunter, op. cit., preface.

32 See, for example, Daston and Galison, op. cit., pp. 55-I I4.

33 Massey, op. cit., 2005, p. 83.

34 Hunter, op. cit., preface.

35 Hunter, op. cit., Table 2I.

36 Jan van Rymsdyck is typically the only artist credited in art historical discussions of Hunter's atlas. But while he did produce most of the drawings and engraved one of the plates, Hunter employed three other draftsmen and 17 other engravers to produce the 34 plates in this book. See Caroline Grigson, “An Universal Language”: William Hunter and the Production of "The Anatomy of the Human Gravid Uterus", in E. Geoffrey Hancock, Nick Pearce and Mungo Campbell (eds), William Hunter's World: The Art and Science of Eighteenth-Century Collecting, Farnham, 2015, pp. 59-80.

37 Sachiko Kusukawa, Picturing the Book of Nature: Image, Text, and Argument in SixteenthCentury Human Anatomy and Medical Botany, Chicago and London, 20I2, p. 2 I 5.

38 Hunter, op. cit., preface.

39 Massey, op. cit., 2005, p. 8 I.

40 McGrath, op. cit., p. 89.

4I Ibid.

42 Plato and Aristotle both described art as mimetic, a mirror of nature. See, for a summary, Noël Carroll, Philosophy of Art: A Contemporary Introduction, London and New York, 2002, pp. I9-23. Much later, Leon Battista Alberti urged that the picture plane be treated as a window, through which the subject to be painted is 'seen'. See Leon Battista Alberti, On Painting, (ed. and trans.) Rocco Sinisgalli, Cambridge, 20 I , p. 39. The use of both metaphors in early modern art is discussed in Stoichita, op. cit.

43 Michel Foucault, The Order of Things, London and New York, pp. I9-50; Whiteley, op. cit.

44 Helkiah Crooke, Mikrokosmographia, London, I6I5, p. I94.

45 For histories of early modern midwifery and visual culture, see Adrian Wilson, The Making of Man-Midwifery: Childbirth in England 1660-1770, London, I995 and Lianne McTavish, Childbirth and the Display of Authority in Early Modern France, Aldershot, 2005. Cynthia Klestinec, 'Renaissance Surgeons: Anatomy, Manual Skill and the Visual Arts', 
in Peter Distelzweig, Benjamin Goldberg and Evan R. Ragland (eds), Early Modern Medicine and Natural Philosophy, Dordrecht, 2016, pp. 43-58, p. 44.

47 Sarah Stone, A Complete Practice of Midwifery, London, I737, p. xiv.

48 For a description of how midwives practiced upon the labouring body without looking at it, see William Smellie, $A$ Treatise on the Theory and Practice of Midwifery, London, I 762 , pp. 264-265.

49 For histories of touch in medicine and culture in this period see Elizabeth D. Harvey (ed.), Sensible Flesh: On Touch in Early Modern Culture, Philadelphia, 2003; Cynthia Klestinec, 'Touch, Trust and Compliance in Early Modern Medical Practice', in Anne Whitehead and Angela Woods (eds), The Edinburgh Companion to the Critical Medical Humanities, Edinburgh, 2016, pp. 209-224 and McTavish, op. cit.

50 Eve Keller, 'The Subject of Touch: Medical Authority in Early Modern Midwifery', in Harvey (ed.), op. cit., pp. 62-80, pp. 68-69.

5 I Rebecca Zorach, "“A Secret Kind of Charm not to be Expressed or Discerned”: on Claude Mellan's Insinuating Lines', in RES: Anthropology and Aesthetics, vol. 55/56, 2009, pp. 235-25I, p. 240.

52 Ibid., p. 249.

53 Ibid., p. 243.

54 Sawday, op. cit., p. 4.

55 Michel Foucault, The Birth of the Clinic: An Archaeology of Medical Perception, (trans.) A.M. Sheridan, London and New York, NY, 2003.

56 Duden, op. cit. 